\title{
¿Una comunidad profesional de la obra pública? Empresarios, ingenieros $y$ funcionarios durante la última dictadura (1976 - 1981)
}

A professional community in public works? Businessmen, engineers and public officers during dictatorship in Argentina (1976 - 1981)

\section{Luján Menazzi}

Doctora en Ciencias Sociales por la Universidad de Buenos Aires. Investigadora del Instituto de Investigaciones Gino Germani de la Facultad de Ciencias Sociales (UBA). Investigadora Asistente del CONICET. lmenazzi@yahoo.com.ar
Fecha de recepción:

13.12.17

\section{Resumen}

El artículo indaga la existencia de una comunidad profesional vinculada al desarrollo de obras públicas, durante los primeros cinco años de la última dictadura militar argentina. Para ello se analizan las formaciones disciplinares, carreras profesionales, instancias de encuentro, diálogos, críticas e intercambios de los actores del universo de la obra pública a los fines de determinar perspectivas comunes respecto al sector, su historia y sus necesidades, así como trayectorias y pertenencias entrecruzadas en ámbitos públicos y privados. También, se busca indagar en qué medida tuvo esa comunidad profesional oportunidad de materializar sus orientaciones, cuán porosas fueron las fronteras entre el Estado y la esfera privada en el área de la obra pública en esa coyuntura y las continuidades y rupturas con períodos previos y posteriores.

Palabras Clave: comunidad profesional - obras públicas - ingenieros - empresarios - funcionarios.

Fecha de aprobación:

14.5.18 


\begin{abstract}
This article focuses on the existence of a professional community linked to the development of public works, with crossed trajectories and multiple belongings in public and private areas during the last military dictatorship. Based on the analysis of professional trajectories, meetings and dialogues, critiques and exchanges, the article seeks to investigate the existence of a professional community and in what ways it materialized its orientations within the framework of the last dictatorship. It also seeks to study how porous were the boundaries between public and private fields in the area of public works in that period and the continuities and ruptures with previous times.
\end{abstract}

Key words: professional community - public works engineers - businessmen - public offficers.

\title{
1. Introducción ${ }^{1}$
}

El análisis de los vínculos entre Estado y actores políticos, económicos y técnicos se nutre de diversas corrientes teóricas. Por un lado, a partir de los clásicos trabajos de Oszlak y O’Donnell (1981) y Scokpol (1985) entre otros, el Estado como actor con capacidad de incidencia y objetivos propios se convirtió en tema relevante a analizar, alejándose de perspectivas que subsumían su rol a intereses de clase o a un mero reflejo de pujas sociales. Así, las burocracias se volvieron sugerentes objetos de análisis, en tanto tienen peso en las definiciones e implementaciones de las políticas públicas. ${ }^{2}$

También, cobraron cada vez más relevancia los análisis de las elites técnicas que por dentro y por fuera del Estado constituyeron progresivamente campos disciplinares en diálogo con la conformación de agencias estatales. ${ }^{3}$ A su vez, el cuestionamiento a la identificación entre burguesía y Estado implicó un auge de los estudios sobre empresarios en América Latina a partir de 1975 (Luna Ledesma y Puga Espinosa 2007). ${ }^{4}$

Tal como señala Marques, a pesar de la relevancia dada a las burocracias estatales y las empresas privadas, "son muy escasos los estudios empíricamente basados que intentan investigar la acción de ambos, siendo más raros aún los análisis centrados en las complejas relaciones entre actores estatales y actores privados" (Marques 1999:341). Desde esta perspectiva, en trabajos anteriores se buscó indagar los vínculos entre el gobierno nacional durante la última dictadura militar y cámaras empresarias ligadas a la industria 
de la construcción, actores que, a primera vista, tenían gran afinidad con los postulados ideológicos del Proceso y habían gozado de particular llegada. ${ }^{5}$

Así, se indagaron los vínculos público - privados a través del análisis de los posicionamientos de la Cámara Argentina de la Construcción respecto al Proceso, sus articulaciones y cambiantes vínculos a lo largo del período (Menazzi 2017a). También se indagaron los perfiles de los funcionarios públicos del área de obras públicas, con la finalidad de identificar las trayectorias profesionales y su origen disciplinar (Menazzi 2017b). A partir de estas indagaciones fueron emergiendo nuevos interrogantes respecto a los vínculos público - privados y la permeabilidad del Estado, alejándonos de ideas como influencia, privatización o captura de áreas del Estado, y pensando conceptualmente otras nociones que permitieran iluminar vínculos más lábiles y cambiantes, donde las fronteras entre lo público y lo privado quedaban desdibujadas. Los estrechos vínculos personales, la pertenencia a una disciplina común, los tránsitos por las mismas organizaciones profesionales y empresarias, las trayectorias profesionales cruzadas y cierta unidad de criterio acerca de cuestiones generales y sectoriales daban cuenta de la pertenencia a un universo común por parte de dirigentes empresarios y funcionarios de la cartera de obras públicas. Así, la noción de comunidad profesional resultó más sugerente para avanzar en esta indagación. De acuerdo a Marques:

entiéndese aquí por comunidad profesional un campo asociado a prácticas profesionales y de saber constituidos por la suma de asociaciones y organizaciones concretas, así como y principalmente por la comunión de una determinada visión de sociedad $y$ de su objeto de intervención (...) un ambiente o campo en que los actores concretos actúan (colectivos o no) (...) Como ambiente, la comunidad engloba a los profesionales del sector, sus organizaciones representativas $y$ todas las empresas y entidades que militan en el área (...) así como las relaciones y vínculos entre ellas

(Marques 1998:23).

La noción tiene la virtud de englobar actores públicos y privados matizando la frontera entre ambos, atendiendo a los vínculos informales, personales, profesionales, institucionales, tenues $y$ fluidos en torno a determinado sector de actividad. ${ }^{6}$

En el marco de estas interrogantes, este artículo busca indagar la existencia de una comunidad profesional vinculada al desarrollo de obras públicas en el período inicial de la última dictadura, entre 1976 y 1981, en que la presidencia de facto estuvo a cargo del general Jorge Rafael Videla. ${ }^{7}$ A partir del análisis de las trayectorias profesionales, de las instancias de encuentro y de los diálogos, críticas e intercambios establecidos, se analiza 
en qué medida existía una comunidad profesional vinculada al quehacer de la obra pública y de qué modos tuvo esta comunidad oportunidad de materializar sus orientaciones en ese marco autoritario. Se busca indagar también, cuán porosas fueron las fronteras entre lo público y lo privado y las continuidades y rupturas con períodos previos.

El universo de la obra pública resulta particularmente rico e interesante por varias cuestiones. Se trata de un área con gran incidencia económica, en tanto tiene una importante participación en el PBI, requiere grandes inversiones y temporalidades extensas para materializar resultados. Tiene un alto componente técnico reivindicado por sus protagonistas, y exige vínculos muy estrechos con actores privados de peso. Esto implica que se conforma un universo relativamente estable y cerrado, en el que el ingreso no es tan sencillo, por sus exigencias técnicas y por sus requerimientos de capital en el caso de las empresas. Al margen, resulta central para la economía argentina dado su carácter reactivador, su demanda de mano de obra o como variable de ajuste. Todas estas características ponen en tensión con los criterios políticos y económicos que guían las decisiones sobre regulación e inversión en la materia. ${ }^{8}$

El golpe de estado del 24 de marzo de 1976 generó muchas expectativas en el universo de grandes y medianos empresarios de la construcción por su afinidad políticoideológica. En los primeros años, el gobierno militar sostuvo una importante inversión en obra pública. ${ }^{9}$ En discusión con ciertas representaciones y autorrepresentaciones del Proceso como quiebre y ruptura total, se apunta a indagar las líneas de continuidad más que de ruptura en el universo de los actores ligados al área de obra pública. ${ }^{10}$ Así, resulta útil retomar perspectivas que además de "pensar a la dictadura militar en clave política" (Canelo 2008:16) hacen énfasis en colocar a la Dictadura en la trama de sentido de la historia argentina, y no como algo desvinculado de ésta (Quiroga 2005; Vezzeti 2002). En este sentido, vale la pena observar el entrecruzamiento de actores civiles y militares en la conformación del entramado social que integró el Proceso (Suriano 2005).

La noción de comunidad profesional supone incorporar a actores de diversa clase: individuos (funcionarios, profesionales, dirigentes empresarios, empresarios), instituciones (cámaras empresarias, agrupaciones profesionales, reparticiones estatales), sus respectivos posicionamientos y, por sobre todo, focalizar en los vínculos entre esta variedad de actores. En este sentido se seleccionaron, además funcionarios e instituciones, escenarios, situaciones e instancias varias de intercambio: jornadas de obra pública, cenas y almuerzos de camaradería, festejos institucionales, anuncio de planes y proyectos, inauguración de obras, que nos permiten asomarnos a los rituales, las escenificaciones y las ceremonias, los reclamos mutuos y las representaciones frente a diversos interlocutores. (Hammersley y Atkinson 1994; Taylor y Bogdan 1986). El muestreo de actores, instituciones y situaciones resulta en todos los casos teórico y, gradual, guiado por la teoría emergente (Glaser y Strauss 1967). El foco está puesto en dar cuenta de la existencia 
de la comunidad profesional, por lo que se incorpora al análisis a aquellos funcionarios nacionales y provinciales vinculados a la obra pública que activamente participan de instancias de contacto e intercambio, y se reconocen mutuamente como integrantes de un ámbito común. Se toman principalmente cargos jerárquicos de la Secretaría de Transporte y Obras Públicas a nivel nacional, funcionarios que tuvieron gran estabilidad a lo largo de los primeros años del Proceso y algunos titulares provinciales de relevancia. Respecto a las instituciones del sector, se trata de un universo vasto en que conviven diversos actores que se alían o enfrentan de acuerdo a coyunturas específicas.

Trabajaremos con tres instituciones que consideramos particularmente relevantes, activas, relacionadas entre sí y con el universo público: la Cámara Argentina de la Construcción (CAC), la Asociación Argentina de Carreteras (AAC) y el Centro Argentino de Ingenieros (CAI) ${ }^{11}$ La reconstrucción de trayectorias, posicionamientos, discursos y vínculos de los actores integrantes del universo de la obra pública se realizó cruzando diversas fuentes, principalmente publicaciones periódicas especializadas vinculadas a la construcción, que se hacían eco de los nombramientos y antecedentes de los funcionarios, las celebraciones del sector, inauguraciones, discursos, actos, intercambios epistolares, agasajos, licitaciones, planes, anuncios, leyes, decretos y debates. ${ }^{12}$

El artículo está compuesto por cuatro secciones, siendo la primera esta introducción. El segundo segmento se enfoca en avanzar sobre elementos que nos permitan dar cuenta de la existencia de una comunidad profesional: las trayectorias de funcionarios y dirigentes de organizaciones empresarias y profesionales, intentando detectar coincidencias; los rituales de presentación, las miradas comunes respecto a la historia del sector, sus períodos de oro y decadencia y concepciones compartidas que trascienden lo sectorial, respecto a lo público y lo privado, la técnica y la política. La tercera parte analiza algunas diferencias internas, desaveniencias, decepciones y reclamos. Por último, en la cuarta sección se realizan algunas reflexiones para concluir.

\section{Trayectorias cruzadas, perspectivas históricas y concepciones comunes: la comunidad profesional}

\subsection{Perfiles profesionales de funcionarios y dirigentes: trayectorias cruzadas}

Al inicio del Proceso, durante el gobierno del general Jorge Rafael Videla, se pueden identificar distintos perfiles en los cargos vinculados al quehacer de la obra pública. Caracterizaremos esquemáticamente tres agrupamientos de acuerdo a las trayectorias profesionales de los funcionarios. ${ }^{13}$ 
Los cargos principales a nivel nacional ligados a la obra pública fueron ocupados por profesionalesque tenían larga trayectoria en ese ámbito como funcionarios en distintas reparticiones gubernamentales, asesores y / o directivos de grandes intervenciones públicas. Dentro de ese primer universo, sirven como ejemplo las trayectorias profesionales del Secretario de Estado de Obras y Servicios Públicos, Ing. Federico Camba, el Subsecretario de Obras Públicas, Ing. Federico Alfredo Batrosse; el Subsecretario de Transporte, Ing. Ezequiel Ogueta. En todos los casos se trata de ingenieros civiles egresados de la Universidad de Buenos Aires con extensas trayectorias en ámbitos de gestión pública. Es decir, funcionarios de carrera quienes además sumaban experiencia docente en universidades públicas. En la mayor parte de los casos, estos profesionales podían exhibir contactos o participaciones en instituciones vinculadas al quehacer de la obra pública, como la AAC, la CAC, el CAI, entre otros. Evidentemente, se valoraba sus conocimientos técnicos y su trayectoria profesional, más allá de su afinidad con la dictadura. Este perfil se reiteró en otros cargos de relevancia.

En segundo término, se incorporaron a la gestión algunos individuos con trayectorias relevantes en empresas privadas ligadas al quehacer constructor. Es el caso del Administrador de la Dirección Nacional de Vialidad, puesto de mucha relevancia dependiente de la Subsecretaría de Transporte. Si bien el Ingeniero Gustavo Roberto Carmona, nombrado en ese cargo, tenía cierta trayectoria como funcionario público y con inserción docente universitaria, el grueso de su desempeño profesional se daba como directivo de VIALCO, una empresa privada muy importante dedicada al rubro vial. Al mismo tiempo integraba asociaciones vinculadas al sector, como la AAC. En el plano provincial, la práctica de nombrar empresarios prominentes sin experiencia en la función pública fue más frecuente. El caso más saliente en este sentido fue el del Ministro de Obras Públicas de la Provincia de Buenos Aires, Ing. Pablo Gorostiaga, uno de los dueños de EACA, importantísima empresa constructora, con amplia participación en las organizaciones vinculadas al sector, como la AAC, la CAC y el CAI entre muchas otras. En Córdoba y Santa Fe también se nombró a importantes empresarios que se desempeñaban como directivos de la CAC.

Por último, existe un tercer perfil de relevancia en muchos puestos clave.Al frente de las grandes empresas de lo que algunos autores nombran como el complejo industrial-militar (Canelo 2008; Rougier 2015) se ubicó a militares de vasta trayectoria en esas áreas dentro del Estado (tal fue el caso de Fabricaciones Militares, Servicios Eléctricos de Gran Buenos Aires [SEGBA], y Empresa Nacional de Telecomunicaciones [ENTEL]). Asimismo, en algunas provincias (Entre Ríos, Mendoza) se nombró a integrantes de las Fuerzas Armadas en los cargos de Ministro y/o Secretario de Obras Públicas. Si bien existen ciertos vínculos entre algunos funcionarios de origen castrense y algunos sectores de la comunidad profesional, que analizaremos más adelante, no incorporaremos a los primeros al universo analizado dado que claramente no forman parte de esta 
comunidad, en tanto no comparten formación, eventos, trayectoria profesional, cosmovisiones ni diagnósticos sobre el sector.

Esta revisión de perfiles nos permite realizar algunas afirmaciones preliminares. En primer lugar, los cargos políticos más importantes a nivel nacional, vinculados al quehacer de la obra pública, quedaron en manos de funcionarios de carrera, con vastas trayectorias en el Estado y gran formación técnica en sus áreas (aunque no habían ocupado previamente los mismos puestos). No se buscó renovar los perfiles ni que esos puestos quedaran bajo control militar, exceptuando el caso de grandes empresas de Estado, que, en muchos casos, ya estaban bajo control de integrantes de las FFAA con anterioridad al golpe. En este sentido, la apuesta fue al perfil técnico, preservando la expertise en el sector y estableciendo visos de continuidad más que de ruptura.

Un perfil que se incorporó en ámbitos provinciales y en algunas reparticiones, en sintonía con lo que acontecía en otras áreas, fue el de algunos empresarios notables, con extensas experiencias en el universo privado. En este caso, como veremos más adelante, se buscaba que estos empresarios volcaran sus conocimientos del universo privado a la gestión pública, en un contexto en que se valoraba, aunque con ciertos matices, el rol de las empresas privadas y los empresarios.

En el caso de los dirigentes de entidades empresarias y profesionales podríamos identificar tres perfiles. Por un lado, empresarios prominentes dueños o altos directivos de grandes empresas, dirigentes históricos, activos participantes y fundadores de varias entidades profesionales, empresarias y sociales, que nunca habían asumido cargos públicos (Ing. Cesar Polledo, Ing. Néstor Alesso, Arq. Marcelo Roggio). Por el otro, un segundo grupo con igual trayectoria en el universo privado e institucional pero con alternancia en cargos públicos (Ing. Antonio Lanusse, Ing. Roberto Marghetti, Ing. Guillermo Vila). ${ }^{14}$ En el caso del CAI, a estos perfiles se suma una variante: el de quienes alternaron cargos públicos además de su participación institucional, sin incursiones en la dirección de empresas privadas (tal es el caso del Ing. Alberto Constantini, presidente del CAI durante todo el período). Los directivos solían integrar más de una entidad al mismo tiempo, incluso desempeñando cargos jerárquicos en varias instituciones. ${ }^{15}$

Las dirigencias mostraron gran continuidad en el período y los recambios se debieron a cuestiones generacionales únicamente, sin vinculación con el cambio de gobierno.

Una cuestión particularmente llamativa es la omnipresencia de ingenieros, en particular ingenieros civiles, más allá de la variedad de trayectorias, como funcionarios públicos, empresarios o dirigentes profesionales y empresarios. Ballent (2012) analizó el vínculo estrecho entre el Ministerio de Obras Públicas y los ingenieros a nivel histórico. De hecho, el Ministerio sucedió a la Dirección de Ingenieros, repartición que previamente se encargaba de las obras públicas. ${ }^{16}$ 
Hasta aquí queda en evidencia la pertenencia a una disciplina común y el tránsito por las mismas instituciones profesionales y empresarias. A continuación analizaremos otros puntos de contacto.

\subsection{Rituales y presentación de credenciales: empresario, funcionario, ingeniero y constructor}

Las instituciones vinculadas al quehacer de la construcción tenían instancias de celebración, festejo e intercambio en que consolidar o resignificar las relaciones. ${ }^{17}$ Estos rituales se repetían anualmente y constituían un termómetro del humor del sector. En estas reuniones se producía "el encuentro de viejos compañeros de trabajo" y dialogaba la "familia vial". Los eventos eran reproducidos en los órganos de prensa de la entidad organizadora y de las entidades amigas así como prensa vinculada, de modo que alcanzaban cierta repercusión. La repetición de las mismas figuras del universo público y privado en todos los eventos y la reproducción espejada de los mismos ayudaba a consolidar una imagen de unidad y un discurso común.

El poder público, por su parte, tenía también sus rituales. Las inauguraciones de grandes obras, el anuncio de planes y licitaciones constituían instancias de puesta escenográfica en que mostrar los logros de cierta agencia gubernamental frente al resto del sector y el gobierno. Estos anuncios en ocasiones se realizaban en reparticiones públicas, pero también se realizaban en instituciones "amigas".

La celebración de estos rituales resulta elocuente respecto a la existencia de una comunidad, un universo común cuyos vínculos se refuerzan y resignifican en estas instancias. Estos eventos, a su vez, resultaron escenarios privilegiados para ver los primeros intercambios y presentaciones de los nuevos funcionarios, sus posicionamientos y credenciales, dando cuenta de qué antecedentes, trayectorias y argumentos eran considerados válidos para legitimarse unos frente a otros y qué fidelidades, deudas y herencias se explicitaban.

Los funcionarios apelaban a diversas estrategias para presentarse. Aquellos con extensa trayectoria en ámbitos públicos, se proclamaban amigos y viejos conocidos, colegas e integrantes de un universo compartido:

Permítaseme despojarme de la solemnidad y el acartonamiento que seguramente confiere a mi figura la presentación que acaban de hacerme en calidad de funcionario, en este momento el que habla es el amigo (...)

(Ing. Federico Camba, Secretario de Transporte y Obras Públicas, 1976a) 
En los casos en que las trayectorias se hubieran desarrollado principalmente en el universo privado, los funcionarios apelaban a ese pasado para autolegitimar su nombramiento en cargos públicos y reforzar los vínculos de familiaridad con los empresarios y profesionales de la construcción. Así, en algunos casos queda en evidencia cierto desdibujamiento de los roles de funcionario público, en tanto reivindicaban y valoraban más su condición de empresario:

Hoy aquí me encuentro trayendo la palabra oficial, pero no puedo despojarme de lo que llevo en lo más profundo de mí; y que hasta hace un poco más de tres meses desempeñaba a través de la presidencia de la Cooperativa de Constructores y la Secretaría de la Cámara Argentina de la Construcción: mi lugar en el quehacer de la construcción. Hoy, aquí, estoy en familia, veo los rostros de todos los que hacen al construir en nuestro medio, con los que he compartido de una u otra forma mis años de profesión a través de las distintas actividades en que me tocó actuar. Esta tarea de dieciocho años me obligó hoy más que nunca a esta tarea oficial que hoy desempeño, que todo lo que hasta ayer esperé y deseé como empresario de parte del Estado, pueda en la medida de lo posible hacerlo realidad en bien de la normalización de las relaciones Empresario - Estado (Ing. Ángel Luis Moia, Subsecretario de Obras Públicas de Entre Ríos 1977).

El puesto público era vivido como circunstancial y secundario, respecto a la verdadera identidad, anclada en la condición de empresario. Así, Carmona afirmaba, luego de relatar su pertenencia histórica a la Asociación Argentina de Carreteras:

Hoy, por uno de esos avatares de la vida, me toca a mí, quien de una u otra forma siempre estuve ligado a esta institución, rendir a ustedes mi examen como responsable de la conducción de la vialidad del país

(Ing. Carmona, Administrador de la Dirección Nacional de Vialidad 1976a).

Las metáforas utilizadas “rendir examen” "volcar la experiencia del ámbito privado a la función pública” o cumplir en el ámbito público las históricas aspiraciones de los empresarios, daban cuenta de la dispar valoración de cada uno de los universos. 
Por su parte los empresarios no renegaban de esta familiaridad. Quienes asumían la función pública provenientes del campo empresario, eran agasajados y felicitados. Se valoraba su espíritu de sacrificio:

La convocatoria a la conducción de las reservas morales y de la aptitud intelectual, y el renunciamiento generoso a la placidez inefable de la vida hogareña, que es la palabra de orden en este presente preñado de expectativas esperanzadas, toma en su designación una expresión concreta (Ing. César Polledo, Presidente de la CAC en carta a Eduardo Oliva, ex Presidente de la CAC Delegación Santa Fe nombrado Ministro de Obras Públicas de esa provincia, 1976a).

Los fragmentos dan cuenta de una pertenencia común y lazos de familiaridad. En este marco, la gestión a encarar es conjunta y atraviesa al universo público y privado por igual:

es muy dificil la tarea que nos toca emprender y quisiera que todos los que están vinculados al quehacer vial se sientan convocados por que la tarea inmediata será ardua y laboriosa (Ing. Carmona, Administrador de la Dirección Nacional de Vialidad (1976b).

cada uno separadamente y todos en conjunto, somos actores con papeles preponderantes a representar en su respectiva esfera de acción

(Ing. Alesso, Presidente de la AAC, 1976).

Se observa que además de reforzar los lazos de familiaridad, se buscaba establecer responsabilidades compartidas, conformar una suerte de equipo que trascendiera las delimitaciones de lo público y lo privado y apelara a la pertenencia a un mismo sector de actividad.

Es esta pertenencia sectorial común, esta cercanía y esta confianza la que permite a los nóveles funcionarios solicitar paciencia, sacrificio y comprensión a los empresarios del sector:

El gobierno espera del patriotismo de sus empresarios, la actitud comprensiva que siempre han demostrado (Ing. Camba, Secretario de Transporte y Obras Públicas, 1978a:8). 
Simplemente pido (...) la suficiente comprensión de parte de todos mis colegas interesados en el sector (...) Comprometo desde ya -aunque resulte obvio para quienes conocen mi trayectoria- que el apoyo a la obra pública a través de mi gestión y de mis colaboradores, no será de ninguna manera retaceado

(Ing. Camba 1976b).

La última cita es interesante por varias cuestiones. Camba, máxima autoridad en obras públicas, no saca a relucir sus cualidades políticas o su compromiso con las ideas del nuevo régimen militar, sino que es su trayectoria profesional la que respalda y garantiza su fidelidad hacia el sector de la construcción, y es esgrimida para generar confianza en los empresarios. Es a partir de la confianza en ese compromiso con el sector que se puede solicitar paciencia y comprensión.

Lo interesante es que los dirigentes empresarios hacen suya esta solicitud y piden paciencia a sus dirigidos:

Como se ve, muchas son las necesidades y grandes los esfuerzos para satisfacerlas (...) Larga y dura será la tarea. No nos entreguemos a las impaciencias ni nos sumemos incautos a las maniobras de los detractores (Alesso, Presidente de la AAC, 1976).

En el caso de la CAC el pedido de paciencia implicó que ante la asunción de las Fuerzas Armadas se pidiera a las empresas el esfuerzo de no paralizar las obras "como patriótica contribución a las autoridades".

En este sentido, muchas veces, los dirigentes parecían emitir discursos propios de los funcionarios, solicitando paciencia y comprensión. A su vez, como contrapartida y como veremos más adelante, los funcionarios emitían discursos con contenidos propios de los empresarios.

\subsection{Una cosmovisión compartida: periodizaciones y reclamos comunes}

Funcionarios, dirigentes empresarios y profesionales tenían una mirada común respecto a la historia de la obra pública, sus épocas de oro, sus períodos de desgracia y sus hombres célebres. En este sentido, nuevamente, el discurso parece uno, sin distinguir entre quienes tenían funciones públicas a su cargo y quienes permanecían en el ámbito privado.

El momento considerado fundacional (y, al mismo tiempo, época dorada) para la obra pública así como para las empresas argentinas de la construcción era la década de 1930: 
Merece destacarse en este período, la realización de obras de infraestructura, como las de Vialidad, Obras Sanitarias, Elevadores de Granos, Ferrocarriles, etc. Que dieron prestigio a nuestro país entre las naciones más desarrolladas del mundo. El dictado de leyes que permitieron el recurso genuino, las estructuras administrativas adecuadas (...) Vinculan su nombre al progreso del país ingenieros como Justiniano Allende Posse, Enrique Butty (...) (Ing. Constantini, Presidente del CAI 1976: 3).

El advenimiento de los dos primeros gobiernos del general Perón (1946 - 1955) representa para estos sectores la debacle. Siguiendo el relato de Constantini, "La inversión en obras rentables es sustituida por inversión en obras que sólo producen dividendos políticos" (ídem)

Polledo, por su parte afirmaba:

al mismo tiempo, se paralizó la obra vial, al punto que eran más los caminos que se destruían que los que se ejecutaban. En cambio, se hacían obras de propaganda política, colonias de veraneo y se construían piletas de natación que constituían el mayor orgullo del ministro (...) 1955, año en que se pone fin a un gobierno que recibió un país enriquecido y poderoso y lo entregó en la miseria económica, en la miseria social y en la miseria cultural (Polledo, Presidente de la CAC 1976b).

Siguiendo este relato, luego de las gestiones del general Perón, se sucedieron gobiernos que intentaron poner orden pero no lograron modificar la matriz perniciosa instaurada por éste. Esta narración histórica llega hasta el momento del golpe de estado de 1976, en que se reabre la "esperanzada expectativa" de retornar a las bases de la década del 30, en términos de vuelta al orden, autarquía financiera y priorización de la obra pública por sobre la búsqueda del rédito político. Este relato histórico era suscrito por los funcionarios, quienes también reiteraban la necesidad de volver a las bases de aquella década.

La visión compartida sobre los avatares históricos del sector, suponía también coincidencias respecto a sus problemas, diagnósticos y necesidades, producto justamente de esa historia.Así, la necesidad de crear un Ministerio de Obras Públicas que unificara y aglutinara al sector, la necesidad de una ley de obra pública que ordenara y homogenizara, la importancia de destinar cuantiosos fondos a las obras públicas, la autarquía financiera respecto a las veleidades de las autoridades políticas y de la cartera económica, eran reclamos que atravesaban a todos los actores, difuminando las diferencias entre quienes ocupaban cargos públicos y quienes se pronunciaban desde el sector privado. 
Si bien los acuerdos trascendían las fronteras entre lo público y lo privado, en el caso de los funcionarios se veían obligados a justificar qué era lo que impedía la consecución de estas necesidades del sector. Aquí, aparecían elípticamente, figuras que bloqueaban el cumplimiento de estos objetivos, como la burocracia, la política o los designios económicos del gobierno.

Por ejemplo, Roberto Agüero Olmos, Administrador de la Dirección de Vialidad de la Provincia de Buenos Aires, al referirse a la autarquía de las direcciones de vialidad afirmaba "no es posible estar discutiendo con los señores de Hacienda lo que Vialidad debe hacer" (Agüero Olmos, Administrador de la Dirección de Vialidad de la Provincia de Buenos Aires, 1977:4). O Camba, al criticar las demoras en la sanción de la ley de obra pública:

siguiendo una tradición más que negativa, nefasta en el país, que ha sido generadora de burocracia genuina, cada jurisdicción se reserva el derecho de encarar el tema desde un punto de vista perfeccionista (...)

(Camba, Secretario de Obras Públicas, 1980:10).

Si bien las críticas a otros sectores del Estado eran más bien veladas, el tono era propio de alguien que se encontraba por fuera del aparato estatal más que de un funcionario. Carmona, por su parte, al reclamar fondos frente a altas autoridades nacionales afirmaba:

Vialidad Nacional siente la imperiosa necesidad de continuar haciendo su obras (...) pero para alcanzar esas metas es necesario que el ente caminero nacional cuente con recursos propios estables $y$ definitivamente programados a través del tiempo

(Carmona,Administrador de la Dirección Nacional de Vialidad 1976c).

En muchos comentarios, los funcionarios replicaban antiguos reclamos, diagnósticos y demandas de las organizaciones del sector como si no tuvieran autoridad o poder alguno en la materia. De hecho, hay ocasiones en que estos reclamos se repiten literalmente, de modo que el discurso resulta ser uno sólo, enunciado por diversos emisores.

Esta unidad de criterio conducía a que muchas veces las decisiones, los proyectos y los trabajos se realizaran de modo consensuado, trabajando a la par.Así lo afirmaban los protagonistas en numerosas instancias. Además de la interacción por gestiones específicas, la Secretaría de Obras Públicas inició en 1978 las Jornadas de Obra Pública, instancia de trabajo participativo en que se armaban comisiones temáticas con participación de diversas reparticiones estatales, representantes de instituciones vinculadas, dirigentes empresarios, etc. En un contexto de cierre político, se abrían estas instancias de diálogo con actores afines donde los consensos y reclamos se realizaban entre pares. 


\subsection{Miradas cruzadas sobre técnica y política, lo público y lo privado}

De acuerdo a lo visto hasta ahora, los funcionarios, empresarios y profesionales compartían ciertas perspectivas respecto a la historia del sector, sus necesidades, problemas y soluciones. También existía cierta perspectiva común respecto a quiénes obstaculizaban al sector: la burocracia, las decisiones económicas contrarias a la inversión pública, la política. Compartían, además perspectivas más generales respecto a la sociedad y el Estado. Nos detendremos en particular en ciertas miradas acerca de nociones que solían contraponer: técnica y política, lo público y lo privado.

Lo político era visto como el terreno de lo arbitrario, discrecional e interesado. En contraposición, se postulaba lo técnico, lo objetivo, considerado indiscutible y equitativo. La gestión del Proceso en todas sus reparticiones comenzó ordenando (lo que denominaron período ordenancista) para completar las obras iniciadas y conseguir financiamiento genuino. Esto fue de la mano de una racionalización administrativa en la Secretaría de Obras Públicas y las reparticiones dependientes de ésta, que supuso la expulsión de 50.000 empleados (Camba 1977). El orden, la racionalidad y los criterios técnicos eran los valores más reivindicados por los funcionarios que asumieron a partir de 1976, y muy valorados por el resto del universo de los empresarios y profesionales de la construcción: "Ofrecemos racionalizar y rigorizar (sic) la conducta del Estado. Sabemos que esa es preocupación común” (Camba, Secretario de Obra Pública, 1978b:9) Desde esta perspectiva, las obras debían priorizarse de acuerdo a criterios técnicos, no políticos.

de ninguna manera las obras se manejan con criterio político. En otras palabras, creo en la tecnología, creo en la planificación y no creo en el amiguismo y en el dedismo (Caballero,Administrador de la Dirección Nacional de Vialidad, 1983:10).

Esta contraposición entre lo político y lo técnico tenía un vínculo estrecho con el tema del financiamiento de las obras, cuestión nodal para la industria. Quienes integraban el universo de la construcción tanto en cargos públicos como desde puestos privados, reclamaban que el financiamiento de las obras fuera genuino (es decir, con impuestos que tenían esa finalidad) y que debía haber autarquía en el uso de esos fondos, no depender de las coyunturas políticas, "los recursos a crear deberán serlo independientemente de las posibilidades presupuestarias coyunturales” (Osvaldo Fernández, Administrador de la Dirección de Vialidad de la Provincia de Buenos Aires, 1976:14).

Vinculada a la dicotomía política / técnica, aunque con otras connotaciones, resulta interesante la contraposición entre los sentidos y valoraciones que se le otorgaban a lo público y lo privado. En el caso de lo público, se asociaba a lo político, es decir, al interés, 
la demagogia, el despilfarro. En contraposición, lo privado era valorado como ámbito de sacrificio y de esfuerzo, lo meritorio, lo racional, lo previsible. En este sentido, era muy bien vista la asunción de hombres provenientes del universo privado, en tanto su experiencia en ese universo podía ser volcada en los cargos públicos. En esa dicotomía universo público / universo privado - empresario, el segundo es el que otorgaba status, legitimidad, aprendizaje, conocimiento y valor que después se intentaría (con mayor o menor éxito) trasladar al fangoso ámbito de lo público.

\section{Desacuerdos y decepciones: las tensiones de la comunidad}

\subsection{Desacuerdos: Liberales versus desarrollistas}

Hemos repasado un universo compartido de formación disciplinar, rituales, perspectivas históricas, diagnósticos comunes acerca de los problemas, necesidades y soluciones para el sector así como miradas y valoraciones más generales acerca de la técnica, la política, lo público y lo privado. Este universo común que integraba a empresarios de la construcción, los funcionarios nacionales (y en algunos casos provinciales) y profesionales de la ingeniería presenta sin embargo, algunas grietas. La diferencia principal se daba con las perspectivas económicas y políticas del CAI, la organización "profesional" y no empresaria. Tanto los funcionarios como los empresarios compartían la perspectiva liberal sostenida por el Ministerio de Economía, en particular apoyaban el principio de subsidiaridad del Estado y el achicamiento de la presencia estatal de la economía (excepto en la obra pública, por supuesto). El CAI, en cambio, tenía posicionamientos más cercanos al desarrollismo, una postura de defensa de la industria nacional que chocaba de bruces con los postulados económicos de la dictadura, pero establecía acuerdos con otros sectores de las Fuerzas Armadas que defendían el intervencionismo estatal y el industrialismo. Las manifestaciones sumamente críticas del CAI acerca de la política económica comenzaron tempranamente y no cesaron a lo largo de todo el período, llegando a generar conflictos internos en la propia institución y con representantes de otras agrupaciones del universo de la construcción, que preferían mantener un perfil más cercano al régimen. ${ }^{18}$ Se apuntaba contra el desmantelamiento de áreas del Estado, la pérdida de profesionales en diversas reparticiones y el proceso desindustrializador que veían como consecuencia de las políticas económicas implementadas.

Los funcionarios de origen castrense, a cargo de algunas de las empresas de Estado y del complejo militar - industrial también sostenían posturas desarrollistas que colisionaban con los postulados del Ministerio de Economía y confluían con las críticas del CAI. En este sentido, podemos afirmar que algunos de los quiebres o diferencias al interior del Estado, en las carteras vinculadas a la obra pública daban cuenta de las internas del propio gobierno militar pero también reflejaban especificidades y grietas entre actores del sector de la obra pública. Esta diferencia se marcó a lo largo de todo el período, sin 
invalidar que las entidades continuaran actuando de modo conjunto en innumerables gestiones e instancias, que siguieran compartiendo rituales e integrantes.

\subsection{Reproches y decepciones}

Dada esta unidad de diagnósticos y criterios que aunaba a los actores vinculados a la obra pública, más allá de su condición de funcionario, dirigente empresario o profesional, llama la atención la decepción que comienzan a manifestar los profesionales y empresarios respecto al desempeño del Proceso. Si había acuerdo respecto a los diagnósticos y necesidades del sector ¿por qué no lograban el resultado esperado al avanzar en los primeros años del régimen, con continuidad en los funcionarios a cargo?

Los reclamos y reproches surgieron de ambos lados del mostrador. Por el lado de los empresarios, se reclamaba que el gobierno resultó tímido en la puesta en práctica de los postulados filosóficos que sostenía, en particular, el principio de subsidiaridad del Estado y la privatización o eliminación de empresas de Estado. Respecto a las críticas específicas a las políticas del sector, se reprochaba la falta de cumplimiento de algunas viejas demandas como la creación de un Ministerio de Obra Pública, una Ley de Obra Pública, reconocimiento adecuado de variaciones de costos y, sobre todo, el nivel de inversión en obra pública. Si bien las disconformidades eran explicitadas en las instancias de encuentro e intercambio, nunca eran achacadas a los funcionarios del sector, sino a instancias más elevadas del gobierno político y económico. ${ }^{19}$

Los profesionales nucleados en el CAI tenían una perspectiva algo distinta. También consideraban que el problema no radicaba en los funcionarios a cargo del sector sino en los responsables de las orientaciones políticas y económicas. Sin embargo, la matriz de crítica era contraria a la de los empresarios. Si para estos últimos el problema fue la timidez, para los profesionales el problema fue la orientación liberal (y no desarrollista) seguida por el gobierno, lo que llevó a tempranas posturas muy críticas para con la conducción económica.

A su vez, los funcionarios también esgrimieron reclamos hacia el comportamiento empresario:

(...) yo quiero hacer algunas reflexiones frente a los señores contratistas de obras públicas, a los señores empresarios de la construcción, de cuyo ámbito yo también he salido. Se han creado en estos dos años condiciones de sinceramiento de precios (...) dentro del esquema de libertad en que estamos viviendo para cotizar las obras $\gamma$, con un programa de inversiones del monto que he mencionado, nos asustan realmente los precios con que 
se están presentando. (...) La época de la renegociación de contratos, de la modificación fácil, del cambio de items, entendemos que se debe superar

(Carmona,Administrador de la Dirección Nacional de Vialidad, 1978:12).

Como se advierte en los extractos, había cierta expectativa acerca de un comportamiento "digno" de los actores privados una vez que el Estado se normalizara y estableciera el clima de libertad tan esperado. El comportamiento inadecuado era atribuido a que previamente el Estado había distorsionado las reglas del juego. Una vez que la dictadura racionalizó y ordenó el aparato estatal y clarificó las reglas del juego se esperaba una actitud a tono del universo privado, pero no ocurrió. El reproche es elocuente por varios motivos. En primer lugar, se reitera la pertenencia común al universo empresario. A partir de esa pertenencia común, se fundamenta la interpelación al correcto comportamiento y se apelaba a valores como la dignidad, franqueza, sinceridad, considerados propios de los empresarios. En contrapartida, se atribuye al Estado la causa primigenia de la distorsión, siendo los empresarios inocentes. A partir de este planteo, es que se vuelve inexplicable o decepcionante la actitud de los contratistas.

Los reproches mutuos entre empresarios y funcionarios no suponen un quiebre en su universo compartido. Al contrario, ambos valoraban la etapa como la más provechosa para los vínculos empresarios - Estado, debido al diálogo fluido y la buena disposición de ambas partes. Así lo confirman los balances y discursos de despedida y también el recambio que trajo la designación del generalViola como presidente en 1981, que puso en evidencia el fin de una etapa y el quiebre del universo compartido que primó durante las gestiones del general Videla.

A partir de la asunción de Viola, hubo algunas buenas nuevas para el sector, como la creación del Ministerio de Obra Pública y la incorporación de algunos directivos del CAI y de la CAC en cargos públicos. Sin embargo, en los puestos más importantes se incorporaron militares con trayectorias y perspectivas muy distintas a los funcionarios previos. Los discursos de los nuevos funcionarios de origen militar distaban de la homogeneidad y comunidad previas, las fidelidades eran hacia el gobierno de facto y las orientaciones económicas que éste definiera, y a esto debía atenerse la industria de la construcción. Las miradas eran de ajenidad hacia muchos de los acuerdos del sector y de familiaridad con el universo militar. ${ }^{20}$ En este sentido, lo que aquí designamos como comunidad profesional vinculada al universo de la obra pública dejó de tener acceso privilegiado a las decisiones gubernamentales, y pasó, temporalmente, a una retaguardia. 


\section{Recapitulación y conclusiones}

En trabajos previos se indagó sobre el vínculo entre actores públicos y privados ligados a la obra pública. En esa indagación, se comenzó a advertir a nivel empírico, que los vínculos entre el universo privado y público ligado a la construcción eran estrechos y que había trayectorias profesionales y disciplinares comunes, además de coincidencia en las perspectivas de los actores. La frontera entre lo público y lo privado no resultaba útil para comprender los posicionamientos, en tanto quedaba diluida frente a una perspectiva común respecto al sector, su historia y sus necesidades. En este marco, se comenzó a trabajar con la noción de comunidad profesional, que, además de dar cuenta de actores heterogéneos como funcionarios, organizaciones, reparticiones estatales y cámaras empresariales, da cuenta de vínculos lábiles y cambiantes.

Así, este artículo se planteó indagar la existencia de una comunidad profesional ligada a la obra pública durante los primeros años del Proceso, bajo las gestiones del general Videla. El período reviste particular interés, en tanto, muchas representaciones y autorrepresentaciones del Proceso denotaban un corte total y abrupto con lo anterior, una reorganización profunda de todos los sectores de la sociedad. Ello no obstante, vale la pena hacer dos señalamientos que matizan esta idea de ruptura. Por un lado, al analizar el perfil de los funcionarios y los dirigentes empresarios y profesionales, se advierten más continuidades que rupturas. Por otra parte, los posicionamientos, acuerdos y desavenencias de funcionarios, dirigentes empresarios y profesionales tenían raíces históricas que trascendían a la dictadura aunque dialogaban con enfrentamientos internos del elenco gubernamental. En este punto, cobra sentido la búsqueda de interpretar a la dictadura en la trama de sentido de la historia argentina, y no como algo externo. Las distintas facciones del Proceso sostuvieron alianzas con múltiples actores con orientaciones y perspectivas diversas, que preexistían al golpe de Estado.

Con el objetivo de indagar la existencia de la comunidad profesional se repasaron las trayectorias entrecruzadas, pertenencias institucionales y disciplinares comunes, ritos compartidos, y concepciones similares respecto a las necesidades del sector, su historia y ciertas perspectivas más generales. Consideramos que estas cuestiones son indicadores elocuentes de la existencia de esta comunidad en el período y el acceso a los más altos cargos. Esto nos habilita una serie de reflexiones.

En primer lugar, las fronteras entre lo público y lo privado se ven difuminadas en tanto existía un fluido pasaje de un universo a otro y una perspectiva común de ambos lados. Los cargos públicos en ciertas oportunidades eran percibidos como una instancia coyuntural y secundaria respecto a la identidad de empresarios o dirigentes empresarios, considerada más importante. 
En segundo término, la noción de comunidad profesional nos permite trascender las temporalidades políticas. Si bien analizamos un período específico y el modo en que esta comunidad tuvo acceso a cargos de relevancia, el recambio gubernamental no desactivó a esta comunidad, sino que relegó (relativamente) su acceso a los más altos cargos e implicó cierto recambio en sus figuras. ${ }^{21} \mathrm{~A}$ su vez, muchos de los integrantes de esa comunidad ya habían tenido acceso a cargos públicos en otros gobiernos. En este sentido, la existencia de una comunidad profesional nos permite reflexionar y matizar los recambios gubernamentales y observar las líneas de continuidad en ciertos sectores de actividad y, por extensión, en la orientación política en estos sectores. Si bien no siempre dominaban los más altos cargos de forma directa, se trataba de un grupo de actores con presencia central en el sector, con valores y cosmovisiones comunes y con diversos modos de incidir en las políticas de obra pública.

Resulta muy interesante que el acceso privilegiado a puestos de decisión por parte de esta comunidad no supuso una consecución exitosa de todos sus objetivos. Por el contrario, muchos integrantes de la comunidad se manifestaron decepcionados al finalizar el período. Cabe realizar algunos comentarios a este respecto. En primer lugar, esa decepción no tenía un correlato estricto con el desempeño del sector en el período. Por el contrario, los datos de desempeño del sector indican que éste fue bueno hasta $1980 \mathrm{y}$ comenzó a descender a partir de esa fecha.A su vez, cabría indagar si la dependencia de esta área de las orientaciones políticas y económicas implicó cierta falta de autonomía que impidió la total consecución de sus objetivos. Por otra parte, tal como se indagó en trabajos previos, el apoyo de parte de esta comunidad a las orientaciones económicas liberales iba, en muchas oportunidades, en detrimento del propio sector (Menazzi 2017a). Por último, otras cuestiones como la incidencia de las burocracias estatales y las internas en el elenco gubernamental pueden resultar iluminadoras para avanzar sobre los avatares de este sector en el período. Quedan estas cuestiones, así como los disensos internos de esta comunidad profesional, como líneas a profundizar a futuro. 
${ }^{1}$ Agradezco los aportes y comentarios de Guillermo Jajamovich, Lucas Iramain y Mariana Gené que me
resultaron muy enriquecedores en diversas instancias del proceso de investigación. ${ }^{2}$ Para un análisis de la corriente neoinstitucionalista histórica, sus potencialidades y limitaciones, ver Marques (1996). El estudio de los elencos gubernamentales tiene antecedentes a nivel local, aunque en términos de Gené (2011) las interrogantes sobre este tema han tendido a ser fragmentarias. Existen diversos abordajes sobre la cuestión. Algunos autores se focalizan en caracterizar el perfil y modalidad de acceso de los elencos (Dalbosco, 2005), otros analizan las destrezas y modos de hacer política de los funcionarios (Gene, 2011). Hay trabajos que buscan regularidades históricas analizando elencos en el largo plazo (Giorgi, 2014), y hay quienes focalizan en determinados niveles gubernamentales, y/o carteras (Suriano, 2012, Heredia y Gené 2009, Ballent, 2012).

${ }^{3}$ Respecto al estudio de intelectuales, expertos y técnicos y sus vínculos con el Estado, ver Neiburg y Plotkin (2004) y Plotkin y Zimmermann (2012) que realizan una reconstrucción de los diversos campos de conocimiento en torno a estos temas.

${ }^{4}$ En el caso argentino, también se puede observar una multiplicación de estos estudios a partir de la década del ochenta, en que la preocupación por la estabilidad del sistema democrático puso en la mira a los grupos de presión. Se destacan los trabajos de Schvarzer e Itzcovitz (1989), Schvarzer (1990), Palomino (1988), Lattuada (1990), Sidicaro (1991) Ostiguy (1990) y Birle (1997) sobre el comportamiento de los grupos y asociaciones empresarias y, más recientemente, los trabajos de Beltrán, (2007), Castellani (2009), y Dossi, (2009).

${ }^{5}$ La última dictadura militar argentina se inició con el golpe de estado del 24 de marzo de 1976 y finalizó el 10 de diciembre de 1983. Fue un régimen que cercenó fuertemente los derechos políticos y civiles y dejó un saldo de 30.000 detenidos - desaparecidos. El gobierno autoritario se proclamó como una ruptura absoluta con lo inmediato anterior y una restauración del orden y valores perdidos, autodenominándose "Proceso de Reorganización Nacional". Nos referiremos al gobierno dictatorial indistintamente como Dictadura o Proceso. ${ }^{6}$ Sobre esta noción y sus diferencias con otros conceptos cercanos como Sector o Policy Domain ver Marques (1998). ${ }^{7}$ El general Videla fue uno de los líderes del golpe militar organizado contra el gobierno de Isabel Martínez de Perón el 24 de marzo de 1976. A partir del golpe, se estableció una Junta Militar con representantes de las tres fuerzas armadas (Armada Naval, Ejército y la Fuerza Aérea) que designó a Videla para ocupar el cargo de Presidente de facto durante el período 1976-1978 y luego lo ratificó en el cargo hasta 1981, año en que fue reemplazado por el general Roberto Eduardo Viola.

${ }^{8}$ Desde su creación en 1898, el Ministerio de Obras Públicas experimentó variaciones en su jerarquía institucional, pasando a ser Secretaría dependiente del Ministerio de Economía en diversos períodos, como el que nos incumbe. ${ }_{9}$ Entre 1976 y 1980 la inversión pública bruta en construcciones creció de modo significativo, para luego descender abruptamente a partir de 1980. El consumo de acero para hormigón armado y cemento, que constituye un indicador para comprender el derrotero de la industria también creció durante la primera etapa del Proceso, hasta 1980. Estos datos dan cuenta globalmente de un buen desempeño del sector durante los primeros cuatro años de la Dictadura. Respecto al desempeño de la industria de la construcción se puede consultar CAC (1986), Castellani (2007), Iramain (2010).

${ }^{10}$ En términos generales, el período es caracterizado como un momento de profundas reestructuraciones económicas. Hubo cambios en el rol planificador propio del Estado de bienestar, sus modos de intervenir y la articulación de lo público y lo privado. Sin embargo, tal como señalan numerosos autores, más que un corte absoluto con las orientaciones previas, existió una compleja articulación entre continuidades y rupturas. En el área económica diversas investigaciones observan tanto un quiebre profundo como líneas de continuidad en las políticas y una articulación tensa de liberalismo y corporativismo (Pucciarelli, 2004, Castellani, 2009; Muller y Rapetti, 2001).

${ }^{11} \mathrm{La}$ CAC es una de las organizaciones empresarias más importantes del país en ese período, que concentraba, sin disputa alguna, las demandas de los empresarios de la construcción (Schvarzer e Itzcovitz, 1989). La AAC es una "asociación integrada por dependencias y funcionarios públicos, empresas constructoras, fabricantes e importadores de equipos y asociaciones de automovilismo, para interesar y asesorar a los poderes públicos en los planes de ejecución de obras viales" (AAC, 2017). Se trata de una institución de gran relevancia, activa participante en la cuestión vial. En el caso del CAI, se trata de una organización profesional centenaria y tradicional, que agrupa a los ingenieros, profesionales íntimamente ligados (y que reivindican para sí como pertinencia profesional) a la obra pública. Los vínculos entre estas instituciones son múltiples, en tanto muchas veces comparten dirigentes, realizan iniciativas conjuntas frente a los poderes públicos, participan de los mismos eventos y replican sus demandas y gestiones en sus respectivos órganos de difusión. Muchas veces, las instituciones son "hijas" unas de otras. Tal es el caso de la Cámara Argentina de la Construcción, que nació en las oficinas del Centro Argentino de Ingenieros, o la Asociación Argentina de Carreteras, cuya iniciativa surgió de dirigentes de la Cámara Argentina de la Construcción. 12 Se trata de las publicaciones de diversos actores institucionales, como "Carreteras" (de la Asociación Argentina de Carreteras [AAC]), "Informaciones de la Construcción" (de la Cámara Argentina de la Construcción [CAC]), "Revista La Ingeniería” y "CAI informa” (del Centro Argentino de Ingenieros [CAI]) 
y el periódico "El Constructor". También se recurrió a noticias aparecidas en los medios de comunicación masivos como el Diario La Prensa y el Diario La Nación así como entrevistas radiales transcriptas en estos medios, reproducción de discursos y eventos, decretos de nombramientos de los funcionarios, curriculum vitae y bibliografia secundaria que referencia trayectorias y eventos del sector.

${ }^{13}$ Esta tipología está basada en un trabajo de análisis previo más amplio sobre los perfiles y trayectorias profesionales de los funcionarios en el período (Menazzi 2017b).

${ }^{14}$ En todos los casos, se trata de presidentes de la CAC o la AAC durante el período, exceptuando el caso de Vila que era tesorero y alto directivo de la CAC.

${ }^{15}$ Por ejemplo, el Ing. Alesso, presidente de la AAC entre 1976 y 1984, se desempeñó como vicepresidente de la CAC en 1978 y ocupó otros cargos directivos de esa entidad en ese período.Al mismo tiempo, era un activo socio del CAI. Esta pertenencia múltiple se repite en muchos de los directivos más importantes del sector.

${ }^{16}$ Tal como señalan Ballent (2012) y Palermo (2006), existió un vínculo estrecho de co - constitución entre la conformación de la ingeniería como campo profesional, sus principales instituciones profesionales y universitarias y la formación de reparticiones estatales vinculadas a la obra pública.

${ }^{17}$ La CAC celebraba anualmente el 17 de noviembre, día de la Construcción, con una serie de eventos en cada una de sus delegaciones provinciales que incluían actos, almuerzos, cenas e inauguraciones con participación de entidades amigas y funcionarios de primera línea. El evento central era la cena de camaradería realizada en la ciudad de Buenos Aires, en los salones del Hotel Sheraton o de la Sociedad Rural Argentina, a la que asistían las mayores autoridades del ámbito de la construcción y del gobierno en funciones. La AAC realizaba un almuerzo de camaradería en salones del Automóvil Club Argentino, como festejo por el día del Camino, el 5 de Octubre de cada año. Allí también se convocaba a entidades amigas y los máximos funcionarios a cargo de vialidad. El CAI celebraba el día de la Ingeniería, 27 de octubre, con una comida anual. En este evento, también invitaba a las entidades afines y a funcionarios públicosvinculados con el sector.

${ }^{18}$ Constantini, presidente del CAI, realizó duras afirmaciones en marzo de 1981, en una conferencia de prensa "si se destruye el aparato productivo a través de la política económica implantada hace cinco años se destruyen nuestras estructuras financieras y se destruye el campo, organismo vital para poder mantener nuestras relaciones de intercambio internacional (...) hemos destruido totalmente nuestro país" (Constantini 1981:7) A partir de estas afirmaciones, un grupo de socios solicitó al presidente del CAI que se abstuviera de hacer declaraciones políticas. Entre los firmantes, estaba el ingeniero Roberto Marghetti, quien fuera Presidente de la CAC entre 1976 y 1980. A esta nota respondió la Comisión Directiva con otra misiva firmada por numerosos socios en apoyo a Constantini. Entre los firmantes de la segunda, está el Ing. Alesso, Presidente de la AAC y vicepresidente de la CAC. Es decir, este conflicto atravesó a personajes que habitualmente sostenían posicionamientos comunes. ${ }^{19}$ Por ejemplo, el Presidente de la Cámara en 1977 afirmaba relatando unas gestiones frustradas: "como queda en evidencia con esto, podemos asegurar que aun existiendo como en este caso, una manifiesta y activa buena voluntad en los funcionarios, las cosas no marchan con la agilidad que sería de desear" (Marghetti, Presidente de la Cámara Argentina de la Construcción, 1977:8)

${ }^{20}$ A modo de ejemplo, en los siguientes extractos se advierten las diferencias con las que el flamante Ministro de Obras Públicas, general Diego Urricarriet, se refiere a sus distintos interlocutores. En el caso de un almuerzo en la CAC, inicia su discurso del siguiente modo: "Agradezco la invitación a participar de este almuerzo, tenemos mucho interés en receptar vuestras inquietudes, así como transmitirles nuestra propia impresión de la realidad y la política que, en virtud de ella, deberíamos seguir para lograr los objetivos del Proceso de Reconstrucción Nacional" (Urricarriet, 1981a: 5).Aunque el tono es muy cortés, se aleja mucho del nosotros inclusivo que planteaba el anterior responsable de obras públicas, Ing. Camba, y establece una clara demarcación entre un nosotros (funcionarios gubernamentales con una impresión propia de la realidad) y ustedes (empresarios con inquietudes). El mismo Ministro, en la Escuela Superior Técnica del Ejército inicia su discurso de un modo mucho más familiar" (1981b:5) "No es una formalidad iniciar esta exposición diciendo que me es particularmente grato reunirme con ustedes pues esta casa tiene un significado muy especial para mí, lo mismo que para muchos de ustedes; y volver a ella en esta circunstancia tiene mucho contenido emotivo que no puedo ocultarles”. Además de denotar distancias, cercanías y pertenencias, los nuevos responsables de áreas vinculadas a la obra pública ya no emitían sus discursos desde las necesidades y perspectivas del sector, sino que argumentaban desde la mirada del gobierno dictatorial como un todo. Por ejemplo, el Ministro de Bienestar Social, contralmirante Carlos Alberto Lacoste, quien tenía bajo su égida la Secretaría de Vivienda y el Banco Hipotecario Nacional, afirmaba respecto a las políticas de dicha entidad "También comprendo que ese objetivo es limitado, pues la cantidad de fondos disponibles para esa operatoria, muy probablemente no satisfaga las aspiraciones. Pero diría que en este momento no veo posible que se pueda implementar una política de ese tipo, aceptando, repito, que la vivienda es un problema prioritario. En algún momento, cuando la reactivación del aparato productivo esté lograda podremos volver a conversar sobre ese tema" (Lacoste, 1981:6). La subordinación a la política económica del gobierno era total, marcando una clara diferencia con sus antecesores quienes sostenían como propias las demandas del sector incluso contra las políticas económicas del gobierno que integraban. 
${ }^{21}$ Efectivamente, si bien durante el breve gobierno del general Viola (marzo a diciembre de 1981 los cargos más importantes quedaron en manos de figuras de origen castrense, algunas designaciones en la segunda línea incorporaron a integrantes de la comunidad profesional que delineamos en este artículo. Así, el Ing.Vila, importante directivo de la CAC, fue nombrado Subsecretario de Desarrollo Urbano yVivienda. En las siguientes gestiones del Proceso, también hubo presencia de integrantes de esta comunidad profesional en diversos puestos ligados a la obra pública. En este sentido, aunque no lograron ocupar los principales puestos, continuaron teniendo fuerte presencia en ámbitos estatales y, particularmente, en espacios no estatales. 


\section{Referencias bibliográficas}

Ballent, Anahí (2012) "Burocracia, técnica y política: los ingenieros del Ministerio de Obras Públicas y los golpes de Estado (1930-1943)"Trabajo presentado en Segundo Taller de Trabajo Construcción del Estado y Burocracias Técnicas en América Latina. Siglos XIX y XX, noviembre. Buenos Aires: IDES.

Beltrán, Gastón (2007) La acción empresaria en el contexto de las reformas estructurales de las décadas de los ochenta y noventa en Argentina. Tesis de doctorado, Universidad de Buenos Aires, Argentina.

Birle, Peter (1997) Los empresarios y la democracia en la Argentina. Conflictos y coincidencias, Buenos Aires: Universidad de Belgrano.

Canelo, Paula (2008) El Proceso en su laberinto. La interna militar de Videla a Bignone. Buenos Aires: Prometeo.

Castellani, Ana (2007) "Intervención económica estatal y transformaciones de la cúpula empresaria durante la última dictadura militar (1976-1983)". En Clara Lido; Horacio Crespo y Pablo Yankelevich (comp.) Argentina, 1976, estudios en torno al golpe de Estado. México: El Colegio de México.

Castellani, Ana (2009) Estado, empresas y empresarios. La difusión de ámbitos privilegiados de acumulación en la Argentina entre 1966 y 1989. Buenos Aires: Prometeo.

Dalbosco, Hugo (2005) "Perfil de los funcionarios políticos 1983-1999” Trabajo presentado en 3er. Congreso Argentino de Administración Pública Sociedad, Gobierno y Administración. San Miguel de Tucumán, 2, 3 y 4 de Junio de 2005.

Dossi, Marina (2009) "La acción colectiva de la Unión Industrial Argentina en el período 1989-2002. Un análisis desde su dinámica organizativa - institucional”. Documentos de Investigación Social 10:1-27.

Gené, Mariana (2011) “En torno a los profesionales de la política.Trayectorias, prácticas y destrezas en el ejercicio del poder político desde el estado"Revista Perspectivas de Políticas Públicas. Año 1 No 1:85-107.

Giorgi, Guido (2014) "Ministros y ministerios de la Nación argentina: un aporte prosopográfico para el estudio del gabinete nacional (1854-2011)".Apuntes:Revista de ciencias sociales. Universidad del Pacífico.Vol. XLI, N 74:103-139. 
Glaser, Barney y Anselm Strauss (1967) The discovery of grounded theory: strategies for qualitative research. New York: Aldine Publishing Company.

Hammersley, Martin y Paul Atkinson, (1994) Etnografía.Métodos de investigación. Barcelona: Paidos.

Heredia, Mariana y Mariana Gené (2009) “Atributos y legitimidades del gabinete nacional: sociohistoria de los ministerios de Economía e Interior en la prensa (19302009)". El Príncipe. No 2. La Plata. 109 - 135.

Iramain, Lucas (2010), "Intervención estatal, desempeño empresario y ámbitos privilegiados de acumulación. El caso del sector vial durante la última dictadura militar, Argentina (1976-1981)", H-industri@. Revista de historia de la industria, los servicios y las empresas en América Latina, año 4, No 6:1-27.

Lattuada, Mario (1990) El estado argentino y los intereses industriales (1983-1989). Buenos Aires: CLADE Informes No 1.

Luna Ledesma, Matilde y Cristina Puga Espinosa (2007) "Los estudios sobre los empresarios y la política. Recuento histórico, líneas de investigación y perspectivas analíticas” en Jorge Basave y Eduardo Marques (1996) "Notas críticas a literatura sobre Estado, políticas estatais e atores políticos" BIB: Boletim Bibliografico de Ciencias Sociais. No 43.

Marques, Eduardo (1998) Redes sociais e permeabilidade do Estado: instituicoes e atores políticos na producao da infra-estrutura urbana no Rio de Janeiro. Tesis de Doctorado. Universidade Estadual de Campinas.

Marques, Eduardo (1999) "Estado e Empreiteiras na Comunidade de Políticas Urbanas no Rio de Janeiro” Dados No 42 (2) 00.

Menazzi, Luján (2017a) “Entre las ‘expectativas’ y la ‘desmoralización’: la Cámara Argentina de la Construcción ante la última dictadura militar” En Revista H - Industria Año 11, Nro 20:64-85.

Menazzi, Luján (2017b) “Conduciendo las áreas técnicas del Estado. Perfil y trayectoria de los actores vinculados a la obra pública durante las gestiones de Videla” Ponencia presentada en lasTerceras Jornadas Interdisciplinarias de Jóvenes Investigadores en Ciencias Sociales; San Martín; IDAES - UNSAM.

Müller, Alberto y Martín Rapetti (2001) "Un quiebre olvidado: la política económica de Martínez de Hoz" Revista Ciclos No 21:11-33. 
Neiburg, Federico y MarianoPlotkin (2004) "Intelectuales y expertos. Hacia una sociología histórica de la producción del conocimiento sobre la sociedad argentina” En Federico Neiburg y Mariano Plotkin, comps., Intelectuales y expertos. La construcción del conocimiento social en la Argentina. Buenos Aires: Paidós.

Ostiguy, Pierre (1990) Los capitanes de la industria. Grandes empresarios, política y economía en la Argentina de los años 80. Buenos Aires: Editorial Legasa.

Oszlak, Oscar y GuillermoO'Donnell (1981) "Estado y Políticas Estatales en América Latina: hacia una estrategia de investigación.” En Documento CLACSO Vol. 4. Buenos Aires: CEDES.

Palermo, Silvana (2006) "Elite técnica y estado liberal: La creación de una administración moderna en los Ferrocarriles del Estado (1870-1910)" Estudios Sociales. Revista Universitaria Semestral. Año XVI, No 30:9-42.

Palomino, Mirta (1988) Tradición y poder: la Sociedad Rural Argentina (1955-1983) Buenos Aires: CISEA - Grupo Editor Latinoamericano.

Plotkin, Mariano y Eduardo Zimmermann(2012) “Introducción” En Mariano Plotkin y Eduardo Zimmermann Los saberes del Estado.Volumen I Buenos Aires: Edhasa.

Pucciarelli, Alfredo (2004) “Introducción” En Alfredo Pucciarelli (coord.) Empresarios tecnócratas y militares. Buenos Aires: Siglo XXI.

Quiroga, Hugo (2005) “El tiempo del Proceso” En Suriano, Juan (dir.) Nueva Historia Argentina, Tomo X, Dictadura y Democracia (1976- 2001). Buenos Aires: Sudamericana:33-86.

Rougier, Marcelo (2015) “El Complejo Militar-industrial, núcleo duro del Estado empresario y la industrialización en la Argentina”. En Andrés Regalsky y Marcelo Rougier; Los derroteros del estado empresario en la Argentina. Caseros: Siglo XX-Eduntref: 221-268.

Schvarzer Jorge y Victoria Itscovitz, (1989) Organizaciones corporativas del empresariado argentino. La Cámara Argentina de la Construcción (1960-1985). Buenos Aires: CISEA.

Schvarzer, Jorge (1990) Estructura y comportamiento de las grandes corporaciones empresarias argentinas (1955-1983). Un estudio "desde adentro" para explorar su relación con el sistema político. Buenos Aires: CISEA.

Sidicaro, Ricardo (1991) "De la dictadura a la Democracia: Formatos de relación entre Estado y empresarios en la Argentina de la década del 80" Debate Laboral: Revista Americana e Italiana de Derecho del Trabajo, No 8-9:73-88. 
Skocpol Theda (1985) “El estado regresa al primer plano. Estrategias de análisis en la investigación actual”. En Evans, B. Rueschemeyer, D. y Skocpol, T. (comps.) Bringing the State Back in, Cambridge: Cambridge University Press. Traducción de Fabián Chueca.

Suriano, Juan (2005) “Introducción: Una Argentina diferente” En Juan Suriano (dir) Nueva Historia Argentina,Tomo X, Dictadura y Democracia (1976 - 2001). Buenos Aires: Sudamericana.

Suriano, Juan (2012) “El Departamento Nacional del Trabajo y la política laboral durante el primer gobierno de Yrigoyen” En: Mariano Plotkin y Eduardo Zimmermann (comps.), Los saberes del Estado. Buenos Aires: Edhasa. 56-58.

Taylor, Stephen y Robert Bogdan (1986) “Introducción: ir hacia la gente”. En Stephen Taylor y Robert Bogdan Introducción a los métodos cualitativos de investigación. México: Paidos.

Vezzetti, Hugo (2002) Pasado y presente. Guerra, dictadura y sociedad en la Argentina. Buenos Aires: Siglo XXI.

\section{Fuentes citadas}

Agüero Olmos, Roberto (1977) "Los distintos medios de transporte y sus problemas" Revista Carreteras. Asociación Argentina de Carreteras. Nro. 81; enero-marzo 1977, p. 4

Alesso, Néstor (1976) “La reunión anual de camaradería en celebración por el Día del Camino” Revista Carreteras. Asociación Argentina de Carreteras. Nro. 80; octubre-diciembre 1976, p. 6.

Asociación Argentina de Carreteras (2017) Nuestra Historia; Buenos Aires; AAC. Disponible en: http://www.aacarreteras.org.ar/institucional/nuestra_historia

Caballero, Julio Cesar (1983) “Declaraciones del Ing. Julio Cesar Caballero". Revista Informaciones de la Construcción. Nro. 920.11 de febrero de 1983, p. 10.

CAC (1986) La construcción. Industria del Bienestar Humano - Cámara Argentina de la Construcción 1936-1986, Buenos Aires, CAC.

Camba, Federico (1976a) "Discurso por el 40 aniversario de la Cámara Argentina de la Construcción y Homenaje a Cesar Polledo" Revista Informaciones de la Construcción. Nro. 580, 4 de agosto de 1976, pp. 9-16.

Camba, Federico (1976b) "Discurso del Ing. Camba". Revista Informaciones de la Construcción. Nro. 571.2 de junio de 1976, p. 8. 
Camba, Federico (1977) "Palabras del Ing. Camba" Revista Informaciones de la Construcción. Nro. 649. 30 de noviembre de 1977, pp. 12-14.

Camba, Federico (1978a) "Palabras del Ing. Camba". Revista Informaciones de la Construcción. Nro. 700.24 de noviembre de 1978, p. 8.

Camba, Federico (1978b) “Primeras Jornadas de la Obra Pública”. Revista Informaciones de la Construcción. Nro. 673. 27 de mayo de 1978, p. 9.

Camba, Federico (1980) "Presidió el Ing. Camba el Acto de Clausura de las Terceras Jornadas de Obra Pública” Revista Informaciones de la Construcción. Nro. 801.31 de octubre de 1980,p. 10.

Carmona, Gustavo (1976a). “Obras Públicas: Plan de Obras de la Dirección Nacional de Vialidad para el segundo semestre de 1976”. Revista Informaciones de la Construcción. Nro. 578, 21 de julio de 1976, pp. 3-4.

Carmona, Gustavo (1976b) "El ingeniero Gustavo Carmona asumió el cargo de Administrador Nacional de Vialidad" Revista Carreteras; Asociación Argentina de Carreteras. Nro. 78. abril-junio 1976, p. 16.

Carmona, Roberto (1976c) “Zárate - Brazo Largo. Finalizó el montaje de la estructura metálica del Puente sobre el Paraná de las Palmas” Revista Carreteras; Asociación Argentina de Carreteras. Nro. 79. julio-septiembre 1976, p. 32.

Carmona, Roberto (1978) "Conceptos del Ing. Carmona" Revista Informaciones de la Construcción. Nro. 691. 20 de septiembre de 1978, p. 12.

Constantini, Alberto (1976) "Palabras del Ing. Alberto Constantini" Revista Informaciones de la Construcción. Nro. 571, 2 de junio de 1976, p. 3.

Constantini, Alberto (1981) "Llamado de atención a las autoridades acerca de la magnitud de la crisis imperante” Revista CAI Informa. Nro. 330, 2 de junio de 1981, pp. 7-10.

Fernández, Osvaldo (1976) "Consideraciones del Administrador de la Dirección Provincial de Vialidad de la Provincia de Buenos Aires, Ing. Osvaldo Fernández” Revista El Constructor. Nro, 3.424. 4 de octubre 1976, p. 14.

Lacoste, Carlos (1981) "Precisiones y anuncios sobre la política de vivienda" Revista Informaciones de la Construcción. Nro. 842. 14 de agosto 1981, pp. 5-7. 
Marghetti, Roberto (1977) “XXV Convención Anual de la Construcción” Revista Informaciones de la Construcción. Nro. 638-639. 21 de septiembre de 1977; p. 8.

Moia, Angel (1977) “Los festejos en el interior del país. Discurso por el día de la construcción Entre Ríos” Revista Informaciones de la Construcción. Nro. 606, 2 de febrero de 1977, pp. 4-15.

Polledo, Cesar (1976a) "Nota de felicitación a Eduardo Oliva” Revista Informaciones de la Construcción. Nro 571, 2 de junio de 1976.

Polledo, Cesar (1976b) “El Ingeniero Cesar M. Polledo habló en el Centro Argentino de Ingenieros sobre la evolución de la construcción" Revista Informaciones de la Construcción. Nro. 571.2 de junio de 1976, pp. 3-6.

Urricarriet (1981a) "Disertación del General Urricarriet" Revista Informaciones de la Construcción. Nro. 827. 2 de mayo de 1981, pp. 5-6.

Urricarriet (1981b) "Disertación del General Urricarriet" Revista Informaciones de la Construcción. Nro. 845. 4 de septiembre de 1981, pp. 5-8.

\section{Cómo citar este artículo:}

Menazzi, Luján (2018) “¿Una comunidad profesional de la obra pública? Empresarios, ingenieros y funcionarios durante la última dictadura (1976-1981)?”. Revista Perspectivas de Políticas Públicas vol. 8 No 15:13-40 